\title{
An Aberrant Presentation of Delusional Body Dysmorphic Disorder - Importance of Early Psychiatry Liaison
}

\section{Sir,}

Body dysmorphic disorder (BDD) is often under recognized and characterized by a chronic course and poor outcomes. ${ }^{[1]}$ Given its predilection for presentation in medical or surgical settings, clinicians across the board should recognize BDD early to ensure appropriate interventions and avoid ineffective and potentially risky procedures often demanded by these patients. ${ }^{[2]}$ Mr. A, 30-year-old unmarried male, presented to the orthopedic department with complaints of being "too short." Having previously undergone Ilizarov surgical limb lengthening in both the legs for same complaints, he currently demanded "one more surgery immediately" despite being explained the potential risks. At this point, the patient was referred to psychiatric services for evaluation. Upon interviewing, Mr. A revealed that he had always felt unappealing because of his "short stature" since school days. He would often avoid social gatherings for this reason. Researching on methods to enhance his height became his preoccupation and while doing so, he stumbled on the Ilizarov procedure. To increase the chances of success, he chose to undergo the surgery at Russia. However, the surgery was "unsuccessful" and he also developed postoperative complications and required prolonged hospitalization. Yet, he was adamant on having repeated surgery and was not ready to consider any argument to the contrary. This rigid and inflexible belief about his perceived defect suggested a delusion. The BDD-Yale Brown Obsessive Compulsive Scale score was 28 indicating "severe" body image-related obsessions and compulsions. ${ }^{[3]}$ Due to hostile attitudes toward the treating team and lack of insight, involving him in the therapeutic process was challenging.

This case highlights the unique challenges involved in initiating the therapeutic process among patients with BDD. The prior negative interactions with health-care providers and lack of insight were major hurdles in establishing a therapeutic alliance. Patients with BDD rarely present to psychiatric services as they are convinced about the "true" nature of their presumed deformity. ${ }^{[4]}$ It is important to note that in the present case, the patient presented to psychiatric services after a delay of more than 10 years. Remaining undiagnosed and facing dissatisfaction with cosmetic procedures can worsen the symptoms of BDD and heighten the risk of self-harm. ${ }^{[5]}$ In such scenarios, there is a need to initiate psychiatric treatment early and this may require extensive negotiations with patients. Such negotiations and psychoeducation are currently underway in the present case. To conclude, physicians and surgeons who are commonly the first contact medical personnel should be aware of the aberrant presentations of the disorder to initiate liaison with psychiatric services at the earliest, to prevent poor physical and psychiatric outcomes.

\section{Financial support and sponsorship}

Nil.

\section{Conflicts of interest}

There are no conflicts of interest.

Harshini Manohar, Vikas Menon

Department of Psychiatry, Jawaharlal Institute of Postgraduate Medical Education and Research, Puducherry, India

Address for correspondence: Dr. Harshini Manohar, Department of Psychiatry, Jawaharlal Institute of Postgraduate Medical Education and Research, Puducherry - 605 006, India. E-mail: harshinimanohar1990@gmail.com

\section{REFERENCES}

1. Bjornsson AS, Didie ER, Grant JE, Menard W, Stalker E, Phillips KA. Age at onset and clinical correlates in body dysmorphic disorder. Compr Psychiatry 2013;54:893-903.

2. Phillips KA. The presentation of body dysmorphic disorder in medical settings. Prim psychiatry 2006;13:51-9.

3. Phillips KA, Hollander E, Rasmussen SA, Aronowitz BR, DeCaria C, Goodman WK. A severity rating scale for body dysmorphic disorder: Development, reliability, and validity of a 
modified version of the yale-brown obsessive compulsive scale. Psychopharmacol Bull 1997;33:17-22.

4. Mufaddel A, Osman OT, Almugaddam F, Jafferany M. A review of body dysmorphic disorder and its presentation in different clinical settings. Prim Care Companion CNS Disord 2013;15. pii: PCC.12r01464.

5. Thompson CM, Durrani AJ. An increasing need for early detection of body dysmorphic disorder by all specialties. J R Soc Med 2007;100:61-2.

This is an open access article distributed under the terms of the Creative Commons Attribution-NonCommercial-ShareAlike 3.0 License, which allows others to remix, tweak, and build upon the work non-commercially, as long as the author is credited and the new creations are licensed under the identical terms.

\begin{tabular}{|l|l|}
\hline \multicolumn{2}{|c|}{ Access this article online } \\
\hline Quick Response Code: & Website: \\
\hline
\end{tabular}

How to cite this article: Manohar H, Menon V. An aberrant presentation of delusional body dysmorphic disorder - importance of early psychiatry liaison. J Neurosci Rural Pract 2017;8:309-10.

(c) 2017 Journal of Neurosciences in Rural Practice | Published by Wolters Kluwer - Medknow 